\section{TYPHOID OSTEOMYELITIS OF THE SPINE}

BY

\section{G. A. H. MILLER, M.A., B.M., B.Sc., M.R.C.P. MARK RIDLEY, M.B., B.Chir. \\ AND}

W. E. MEDD, M.D., M.R.C.P.

\section{St. Thomas's Hospital, London}

Osteomyelitis is an uncommon complication of typhoid fever. In view of the rarity of the complication (less than $1 \%$ in most series) and of the infrequent occurrence of typhoid in the British Isles to-day (578 cases in England and Wales during 1957 to 1961 inclusive) the following case is reported.

\section{Case Report}

A married woman aged 45 was admitted to hospital on February 19, 1961, with a two-months history of pain in the back. The pain was felt in the high lumbar region and radiated round the left side of the abdomen at the level of the umbilicus. The pain was made worse by coughing or laughing and was eased by lying down. For three days before admission she had had a fever up to $102^{\circ} \mathrm{F}$. $\left(38.9^{\circ}\right.$ C.). In July, 1960 , she had had pain in the low lumbar region radiating down the left leg. The pain, which had been ascribed to a low lumbar disk lesion, resolved after three weeks rest in bed. In November she was admitted to another hospital with fever, headache, mild jaundice, and a swelling in the right hypochondrium. Acute cholecystitis was diagnosed and penicillin and streptomycin were given for five days. She did not respond to treatment, and a rising antibody titre to Salmonella typhi suggested that this was the infecting organism. Three weeks before this earlier illness she had eaten oysters.

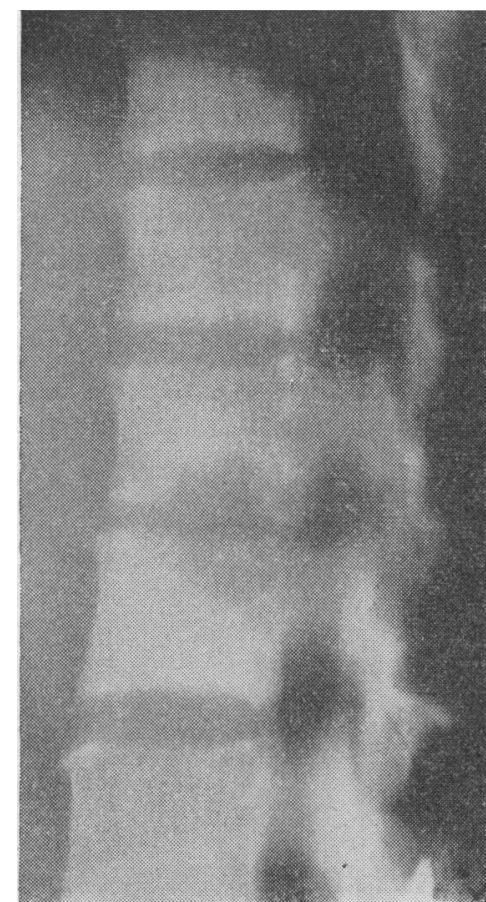

FIG. 1

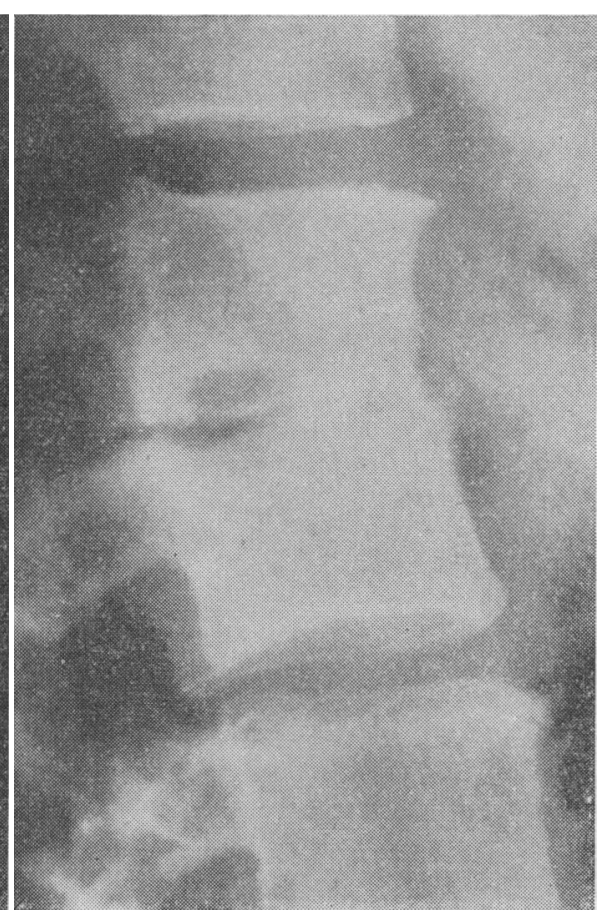

Fig. 2
FIG. 1.-Radiograph taken in February, 1961, showing an osteolytic lesion in the bodies of $L 1$ and 2. FIG. 2.-Radiograph taken in June, 1962, showing bony fusion anteriorly between $L 1$ and 2 .
On examination she was in considerable pain but did not look unwell. The upper lumbar spine was rigid and any movement produced severe pain. Her temperature and pulse were normal. There were no abnormal signs in the central nervous or other systems.

Investigations.-Hb $89 \%$; W.B.C., 4,100/c.mm. (neutrophils $62 \%$, lymphocytes $34 \%$, monocytes $3 \%$, eosinophils 1\%). E.S.R. (Westergren) $42 \mathrm{~mm}$./hr. Serum agglutinations: Salm. typhi, $\mathrm{H}$ positive to titre of 1 in $500 ; \mathrm{Salm}$. typhi, Vi positive to titre of 1 in 80 ; Salm. typhi, O negative; Salm. paratyphi $B, H$ and $O$ negative; non-specific salmonella, negative; Brucella abortus, negative. Three stool cultures grew no pathogens. A catheter specimen of urine grew no salmonellae. Nine blood cultures were sterile. $X$-ray examination, including tomography, of the lumbar spine showed a large osteolytic lesion in the bodies of $\mathrm{L} 1$ and 2 on either side of the disk space, which was narrowed. There was no evidence of sclerosis or new bone formation (Fig. 1).

A diagnosis of osteomyelitis of the first and second lumbar vertebrae was made, and in view of the agglutination tests it was thought that Salm. typhi might be the infecting organism.

At operation by R. J. Furlong on March 9 the left L 1-2 disk space was approached by removal of the twelfth rib and transverse process of $L 2$. A probe was inserted into

\begin{tabular}{|c|c|c|c|c|c|c|c|c|c|}
\hline & \multicolumn{9}{|c|}{1} \\
\hline & & $22 / 11$ & $30 / 11$ & $20 / 2 / 61$ & $7 / 3$ & $26 / 4$ & $13 / 7$ & $30 / 11$ & $25 / 5 / 6$ \\
\hline $\begin{array}{l}\mathrm{Vi} \\
\mathbf{H}\end{array}$ & $\begin{array}{l}1 / \overline{2500} \\
1 / 25\end{array}$ & $\begin{array}{l}1 / 5 \\
1 / 2000 \\
1 / 200\end{array}$ & $\begin{array}{l}1 / 10 \\
1 / 2000 \\
1 / 200\end{array}$ & $\begin{array}{l}1 / 80 \\
1 / 500\end{array}$ & $\frac{1 / 80}{=}$ & $\begin{array}{l}1 / 60 \\
1 / 200 \\
1 / 200\end{array}$ & 1/60 & & \\
\hline
\end{tabular}

the disk space and considerable pus oozed out. The abscess cavity was explored and curetted. The pus yielded a pure culture of Salm. typhi sensitive to chloramphenicol, streptomycin, chlortetracycline, and tetracycline. Histological examination of the fragments curetted from the abscess cavity showed chronic granulation tissue and bone.

She was treated with $2 \mathrm{~g}$. of chloramphenicol a day in divided doses for eight days after operation. She lost her pain immediately after operation, and three weeks later was able to walk with no more than slight stiffness in her back. She did, however, develop a reactive depression which responded well to five treatments with electric convulsion therapy.

$X$-ray films of the lumbar spine taken four months after operation showed calcification or new bone formation anterior to the bodies of $\mathrm{L} 1$ and 2 . $X$-ray films taken one year later showed bony fusion anteriorly between $\mathrm{L} 1$ and 2 (Fig. 2). She has since remained well. The E.S.R. has fallen to a normal value and three subsequent stool and two urine cultures have not grown salmonellae. Agglutination titres to Salm. typhi $\mathrm{Vi}, \mathrm{H}$, and $\mathrm{O}$ have steadily fallen during the months following her illness (see Table).

\section{Discussion}

Osteomyelitis as a complication of typhoid fever was first reported by Maisonneuve (1835), and Erbermaier (1889) was the first to isolate Salm. typhi from an osteomyelitic lesion. Murphy (1916), in an extensive review of the literature, found 164 reported cases of typhoid 
osteitis and periostitis occurring out of a total of 18,840 cases of typhoid fever-an incidence of $0.82 \%$; and Webb-Johnson (1917) reported details of 1,118 cases, of which four had osteomyelitis-an incidence of $0.4 \%$.

Recent interest has centred on cases of osteomyelitis due to salmonellae other than Salm. typhi and on the relationship between salmonella osteomyelitis and sicklecell anaemia (De Torregrosa et al., 1960). Recent reports of osteomyelitis due to Salm. typhi have been of isolated cases, and we have found six cases reported in the literature since 1926.

The bones most attacked are, in order of frequency, ribs, tibiae, and spine ; and these sites account for $70 \%$ of all typhoid bone lesions (Murphy, 1916). Murphy found 88 reported cases of lesions of the spine, and 59 of these were dorso-lumbar, lumbar, or lumbo-sacral. Elkin and Halpenny (1914) found a total of 94 reported cases of involvement of the spine and reviewed 22 of them; all but two had pain in the lower dorsal or lumbar spine.

Radiologically the lesion tends to involve two or more vertebrae, with destruction of the intervening disk space. New bone formation in the surrounding spinal ligaments is a characteristic finding.

In the case reported here the first symptoms of bone involvement occurred three months after the initial infection. Garr (1927) states that $75 \%$ of cases of typhoid osteitis occur during the febrile stage or during convalescence and $25 \%$ months or years later. Murphy (1916) found that $4 \%$ of cases of typhoid bone lesions occurred during the attack, $52 \%$ during convalescence, and $44 \%$ months or years later. Several reports exist in the literature of cases of typhoid osteomyelitis occurring some years after the initial attack, the longest interval being 27 years (Garr, 1927).

\section{Summary}

A case of typhoid osteomyelitis of the lumbar spine is described. After surgical exploration the patient was given chloramphenicol with apparent relief. The incidence and clinical features of typhoid osteomyelitis are discussed.

Our thanks are due to Dr. Evan Jones for permission to report details of a case admitted under his care; to Dr. E. S. Anderson, Director, Central Enteric Reference Laboratory, for bacteriological and serological studies ; and to Dr. Barham Carter for details of the patient's initial illness.

\section{REFERENCES}

Elkin, S. J., and Halpenny, J. (1914). Brit. J. Surg., 1, 602. Erbermaier, A. (1889) Dtsch. Arch. klin. Murg., 1, 602. Garr, C. C. (1927). Sth med. J. (Bgham. Ala). 20,296 Maisonneuve (1835). Thèse d'agrégation. Paris. Quoted by Murphy (1916).

Murphy, J. B. (1916). Surg. Gynec. Obstet., 23, 119.

De Torregrosa, M. V., Dapena, R. B., Hernandez, H., and Ortiz, A. (1960). J. Amer. med. Ass., 174, 354. Webb-Johnson, A. E. (1917). Lancet, $2,813$.

Three Nuffield Fellowships held at the Sheffield Teaching Hospitals and tenable for six months are available each year for selected overseas graduates who have held a registrar appointment in the Sheffield Region for two years. Three overseas fellows have already been appointed and are being accommodated in the teaching hospitals. This scheme, financed by the Nuffield Provincial Hospitals Trust, will give overseas graduates working in the Sheffield Region the advantage of training both in regional and teaching hospitals before returning to their own country.

\section{Medical Memoranda}

\section{Methadone Poisoning in a Child}

Accidental poisoning in children remains a problem of increasing magnitude in all centres in this country. Over the past five years 225 cases were admitted to the Royal Hospital for Sick Children, Edinburgh, the number rising from 32 in 1957 to 56 in 1961. Drugs prescribed for members of the family, or bought across the counter, were responsible for $64 \%$ of our cases, aspirin being the most common ( $24 \%)$, followed by iron preparations and barbiturates ( $11 \%$ each).

Methadone poisoning has received little attention in the British literature. In the medico-legal columns of the British Medical Journal (1951) a child of 3 years was recorded as found dead after drinking a large quantity of "physeptone" (methadone) linctus, and the manufacturers then sent a circular to doctors warning them of the dangers of leaving this potent preparation within the reach of children. Roxburgh and MunroFaure (1951) reported severe respiratory depression in a child of 4 years given an overdose of $24 \mathrm{mg}$. of amidone (methadone) together with $60 \mathrm{mg}$. of phenobarbitone over six hours. Craig and Fraser (1953) list three instances of methadone poisoning in their survey of 500 cases of accidental poisoning in children and quote the Registrar-General's Report on the certified causes of death in 454 fatally poisoned children in which two were due to amidone (methadone).

\section{CASE REPORT}

A boy aged $3 \frac{1}{2}$ years was well until 8 p.m. on April 23, 1962 , when he swallowed approximately $16 \mathrm{mg}$. of methadone. This had been prescribed as a linctus ("physeptone" linctus) for his father's sore throat, the bottle being kept on the bedside table. The parents did not appreciate the danger of the medicine, so no attempt was made at the time to make the child vomit, and he was simply put to bed. Next morning he was unrousable and blue at the lips. $\mathrm{He}$ was admitted to hospital at 11 a.m. on April 24, 15 hours after the drug had been ingested.

Examination on admission showed a well-nourished child, deeply unconscious, cyanosed, with shallow respiration, rate $10 /$ minute, the pulse regular and rate 112 /minute, the bloodpressure $75 / 40 \mathrm{~mm}$. Hg. Excessive secretions were present in the pharynx, and both the gag reflex and the tendon reflexes were absent. The heart sounds were normal in quality, no murmurs were audible, and the femoral pulses were present.

Nalorphine $0.5 \mathrm{mg}$. given at once intravenously produced an increased depth and rate of respiration. The trachea was intubated, the airways were cleared of secretions by suction, and oxygen was given. At $11.30 \mathrm{a} . \mathrm{m}$. the respiratory rate fell again to $12 /$ minute and a further intravenous injection of nalorphine was given with good effect. Half an hour later a third injection of nalorphine was required. The child remained deeply unconscious and the bloodpressure fell to $66 / 40 \mathrm{~mm}$. $\mathrm{Hg}$. In view of this, metaraminol $0.5 \mathrm{mg}$. was given intramuscularly at 12.10 p.m., raising the blood-pressure to $120 / 80$ within five minutes; the effect, however, was sustained only for 15 minutes. At 1 p.m. metaraminol $0.5 \mathrm{mg}$. intravenously and $2 \mathrm{mg}$. intramuscularly maintained the blood-pressure at $100 / 80$ for two hours. By 3 p.m. the pressure had fallen again to $75 / 60$, and a third injection of metaraminol $2 \mathrm{mg}$. intramuscularly was given, and thereafter the blood-pressure remained around $110 / 80$.

Two short convulsions occurred at 5.05 and 6.20 p.m., but shortly after the last the child regained consciousness. 